\title{
Cardiac patients' beliefs about their illness and treatment: A sequential exploratory mixed methods design
}

\author{
Nahid Dehghan-nayeri ${ }^{1}$, Mahboubeh Shali ${ }^{2}$, Atefeh Vaezi ${ }^{3}$, Nasrin Navabi ${ }^{4}$, Fatemeh Ghaffari*4
}

\section{Abstract}

Background: Cardiac patients' beliefs about illness and treatment can disturb their treatment process, treatment regimen adherence, and daily activities. Exploring these beliefs by the use of appropriate, valid, and accurate scales can be helpful in false beliefs reforming by nurses and finally, result in life quality promotion. Therefore, this study is conducted to design and psychometry a questionnaire probing about cardiac patients' beliefs about illness and treatment.

Methods: The sequential combination exploratory mixed methods design was used to develop the questionnaire format, which involved two sections: the quantitative and qualitative step. The qualitative step included probing the role of cultural beliefs about illness and treatment in two steps, including the literature and related tools review and fieldwork (semi-structured interviews with cardiac patients). Seventeen studies were checked in the literature review. Twenty-two cardiac patients were selected and interviewed by purposive sampling. The interviews continued up to the data saturation. The data analysis was conducted in both steps using conventional content analysis and textual content analysis. The quantitative step was a methodology study accomplished in two parts. The questionnaire items were formed using the data and items pool in the first part while the psychometric properties of the questionnaire were checked using face, content and construct validity and the reliability was probed using internal consistency and stability in the second part. The data were transferred into SPSS software program, version 18.0 for Windows $(\alpha<0.05)$.

Results: 319 codes were extracted from the analyzing phase which formed 6 categories including prognosis, prevention, contexts, treatment efficiency, mentality and lifestyle as well as 9 sub-categories including understanding the danger, attitude toward disease, attitude toward treatment, society's culture, feeling hopeless, treatment regimen ignorance, self-curing, trying to survive and physical outcomes.

The items pool was formed using literature reviews and interviews. A 30-itemed questionnaire was formed after the psychometric process. The Kaiser-Meyer-Olkin (KMO) index and the Bartlett's test of sphericity showed good results. Six components from the exploratory content analysis including prognosis, prevention, contexts, treatment efficiency, mentality, and lifestyle gained $51.7 \%$ variance totally. The interclass correlation coefficient was 0.83 in responding to the items for two times.

Conclusion: This study developed a questionnaire about cardiac patients' beliefs regarding their illness and treatment. It can be used for the educational, research, and treatment purposes as a questionnaire with short, easy, and grammatically simple items that have appropriate validity and reliability. Using this scale can be helpful in evaluating clients' beliefs and recognize their educational needs.

Keywords: Belief, Cardiac patients, Tool design, Exploratory mixed methods

Conflicts of Interest: None declared

Funding: Tehran University of Medical Sciences

\section{*This work has been published under CC BY-NC-SA 1.0 license.} Copyright $₫$ Iran University of Medical Sciences

Cite this article as: Dehghan-nayeri N, Shali M, Vaezi A, Navabi N, Ghaffari F. Cardiac patients' beliefs about their illness and treatment: A sequential exploratory mixed methods design. Med J Islam Repub Iran. 2019 (18 Sep);33:98. https://doi.org/10.47176/mjiri.33.98

Corresponding author: Dr Fatemeh Ghaffari, f.ghaffari@mubabol.ac.ir

1. School of Nursing and Midwifery, Nursing and Midwifery Care Research Center, Tehran University of Medical Sciences, Tehran, Iran

2. School of Nursing and Midwifery, Tehran University of Medical Sciences, Tehran, Iran

3. School of Nursing and Midwifery, Zanjan University of Medical Sciences, Zanjan, Iran

4. Nursing Care Research Center, Health Research Institute, Babol University of Medical Sciences, Babol, Iran

\section{$\uparrow$ What is "already known" in this topic:}

There are numerous papers pubished on cardiac patients' beliefs about their illness and treatment but fewer ones presenting an appropriate exploratory tool. Appropriate, valid and accurate tools are needed to evaluate patients' beliefs about illness and treatment.

\section{$\rightarrow$ What this article adds:}

This questionnaire, which we recommend as a mini scale, can be used both in statistical and practical studies. It can be used in health systems as a scale for probing and examining the cardiac patients' beliefs about illness and treatment and it can help for assessing each patient's educational needs. In the other hand, this scale can assess the true or false beliefs; therefore, it can be used for providing the appropriate intervention at the first, second and the third level of prevention based on client needs. 


\section{Introduction}

Heart-related illnesses are amongst the most important ones worldwide. Such illnesses include a wide variety of different heart-related problems such as cardiac ischemia, angina pectoris and acute coronary syndrome which all can increase the chance of getting acute myocardial infarction (AMI) $(1,2)$. Coronary diseases and specially the AMI are among the main reasons of death in Iran as the 2008 reports announce $33-38 \%$ of impact rate (3). Coronary diseases do also affect health, social, and economic domains of society (4).

Reducing the risk factors by reforming the patients' beliefs and concepts is known as an appropriate preventing solution. Patients have less treatment regimen adherence and do not easily match with their illness, treatments, and preventional programs in case they find false beliefs about their disease (5). Such beliefs are founded based on experience and other sources of information which the patient receives from the society or his relatives (6) as the disease-related information can be received from advanced health care providers (the official diagnosis and treatment systems) or the referential systems (family members, friends, and media) or even the computer-based sources (7).

Patients' beliefs are effective in their disability or lifestyle. Those who have more false beliefs about heart diseases have slower recovery pace and therefore, experience high levels of anxiety; as their mental and functional state may be affected too $(8,9)$.

The beliefs regarding the illness and treatment influence over the daily activities and can disturb the treatment regimen adherence. Therefore, it is needed to examine such phenomenon in full details while in case of the lack of any accurate tool, this purpose is inaccessible. There are numerous papers researching cardiac patients' beliefs about illness and treatment (10) but fewer ones presenting an appropriate exploratory tool. Appropriate, valid, and accurate tools are needed to evaluate patients' beliefs about illness and treatment.

Qualitative studies lead to receiving deep data, and by creating a reliable and valid tool from such data, the needs of the clients, and the needed interventions can be recognized more accurately. The researchers of this study started their research based on this fact to provide high-quality care, increase the life quality, and survival probability as the qualitative studies result in (11).

\section{Methods}

The Inductive-Sequential Mixed Methods Design was adopted to develop the questionnaire in this study which is a combination of a qualitative and a quantitative method. The two methods got mixed for data mixing (12). The data were transferred into SPSS software program, version 18.0 for Windows $(\alpha<0.05)$.

\section{Step one: qualitative study}

The patients' conception of illness and treatment was probed in two parts, including the literature and related tools review and field work (semi-structured interviews with cardiac patients) for the qualitative step. Many searches were done for clarifying the concept of beliefs about illness and treatment in literature review using keywords, such as beliefs, cardiac patients, tool design and psychometric tests were searched in google scholar, google, Science Direct and Pubmed databases. Finally, 17 papers were selected for the study. Textual content analysis was used for analyzing the papers. The data analysis process was started with careful papers studying. Afterward, a list of items for the final data check was prepared.

\section{Fieldwork}

The fieldwork step consisted of inviting the cardiac patients hospitalized in CCU or post-CCU wards or the ones referring to the academic heart clinics and hospitals of Zanjan University of Medical Sciences located in Zanjan province, Iran. Participants were selected on the basis of having stable medical conditions, gender, willingness for participation, and having enough communicative skills. The maximum variability for age, gender, educational level, living place, and illness duration was considered. The sampling was purposive. Detailed semi-structured interviews were used for the data gathering.

The interviews were recorded. The interview-guide questions like "would you please tell us how do you feel about the cardiac disease?", "what causes cardiac diseases in your opinion?", "what can make you better?" and "what can make your disease condition worse?" were asked. The next questions were asked by considering the early responses and interview guide. Probing questions like "what do you mean?" or "could you give more details" were designed, if needed. In the end, the participants were asked to state any missed detail or point, and subsequently, they were informed about the possibility of further interviews.

Face-to-face interviews in a quite room in $\mathrm{CCU}$ wards, post-CCU wards, or heart clinics lasting for 35-45 minutes were done. The data saturation appeared when the codes became repetitive, and no new category or subcategory was created after 20 interviews with the patients who had inclusion criteria. The data gathering was ended with two further interviews. Qualitative content analysis was used then for analyzing the data conventionally applying the Granheim and Lundman pattern (13).

The interviews were transcribed word by word right after the end of the talks at this stage. Units were formed initially during the data analysis. The whole transcribed text of each interview has been supposed to be an analyzing unit in this manuscript. The conceptual units were then created which all included the participants' statements regarding different aspects of the main concept. Coding was the next step in which, codes referring to a common concept were categorized in one group while the differences, similarities, and coordination made the subcategories in a steady comparison process. The concealed content and concepts of the data were selected as the main categories then. 


\section{Trustworthiness}

The data gathered in the qualitative step were carefully checked in order to fit the Guba \& Lincoln criteria of credibility, dependability, confirmability, and transferability (14). Peer check and member check were used at this step. To validate the combination study investigator to deal with the threats of data collection in both qualitative and quantitative study we used different participants. Enough sample size capable of getting the data saturation was used in the qualitative step while a bigger size was used in the quantitative step for better validation.

\section{Step two: quantitative studies}

Inductive (items extracted from participants' experiences) and deductive (codes extracted from the literature review) methods were used in the designing of the tool. Interview Codes include: Simplicity of treatment, lack of community due to illness and the impossibility of returning to life before illness. All the related and in-access tools were checked in the literature review in order not to lose any possible item. Literature review Codes include: Permanent consumption of medication, outcome of illness, physical deterioration of the underlying cause of the disease, and cause of the disease. The researcher prepared a draft of items according to the categories and subcategories of "beliefs about illness and treatment" concept (Table 1).

All the possible items were checked, and an item-pool was formed including 58 items. Each item was reviewed by the research team according to the research subject, and the final ones could be used in calculating the constructs. The formal, content, and construct validity was done at this stage.

\section{Face validity}

The face validity was checked in both qualitative and quantitative methods. It is considered as a degree in which the questionnaire appears effective in terms of its stated aims qualitatively. Ten cardiac patients hospitalized in $\mathrm{CCU}$ or post-CCU wards or the ones referring to the heart clinics were asked to comment on difficulty, relevancy, and ambiguous levels in face-to-face interviews to check the face validity qualitatively. Afterward, the item impact method was applied to decrease or eliminate the inappropriate items and determine each item's importance as a quantitative method (15). Participants were asked to score a 5-point scale, from "with no importance" to "very important" in this study. The least point item impact was set to be 1.5 .

\section{Content validity}

Both qualitative and quantitative methods were used to check the content validity. Five cardiologists with sufficient working experience in the clinical and educational settings and four expert nurses with the experience of working at $\mathrm{CCU}$ and post-CCU wards were asked to comment on the grammar, wording, allocation, and scaling of the items. Two indices of CVI and CVR were used to check the content validity quantitatively.

\section{Content Validity Ratio (CVR)}

Lawshe model was used to determine the CVR in this study (16). Ten subject experts (nursing faculty members with the working experience in clinical settings, tool making, and teaching cardiac nursing subjects) were asked to check the necessity of items according to a 3-point scale ( necessary to unnecessary). The results were compared with the scale of Lawshe table.

The minimum acceptable CVR is found to be 0.62 based on the Lawshe's table and 10 master experts' ideas (16). CVR strict was used in this study meaning that only the necessary options were kept in the CVR formula.

\section{Content Validity Index (CVI)}

The CVI was promoted initially by Waltz and Bausell (17). Ten experts (the same people helped in CVR determination) were asked to check if each item fits in the Likert 4-point scale (from absolutely relevant to irrelevant).

In this study, the S-CVI was calculated. It was done to find which item needs to be reformed or eliminated, to know whether any further item is needed to completely cover the related aspect or not and to check that all the aspects of a construct are presented in a correct number of items or not. Then, it was decided to reform or to eliminate the item based on its CVI level. The items with a score of 0.7 or less were candidates for elimination.

\section{Construct validity}

The construct validity is considered as a degree in determining the questionnaire's efficiency in the created constructs $(18,19,20)$. KMO and Bartlett sphericity tests were used before extracting the components. The KMO value of 0.7 or higher was considered as the condition of sample size sufficiency in the content analysis (21). 550 samples were used in this study for the exploratory content analysis (EFA). The minimum factor loading for keeping each item has been set as 0.5 in this study.

\section{Reliability}

The reliability of this study was checked using internal consistency and stability methods. The minimum value of 0.6 was considered for Cronbach's alpha (22). The Testretest and Interclass Correlation Coefficient (ICC) were used to check the stability. The acceptable minimum for ICC was set at 0.4 (23).

Table 1. A sample format for defining the items of the questionnaire.

\begin{tabular}{|c|c|c|c|}
\hline Comments and experiences of the participants & Code & Construct & Item \\
\hline $\begin{array}{l}\text { I shouldn't work anymore. No shopping and no commute. Being } \\
\text { in society is dangerous for me. I feel like staying home. }\end{array}$ & Feeling danger in society & lifestyle & $\begin{array}{l}\text { Cardiac patients should avoid } \\
\text { being in society/social places. }\end{array}$ \\
\hline $\begin{array}{l}\text { I know that nothing can be done for such a damaged heart. Med- } \\
\text { ications help me a little. I have to go on to see what God will do. }\end{array}$ & $\begin{array}{l}\text { The ineffectiveness of } \\
\text { treatment methods }\end{array}$ & Prognosis & $\begin{array}{l}\text { It is impossible to renew a } \\
\text { damaged heart. }\end{array}$ \\
\hline $\begin{array}{l}\text { My father also had a heart problem. I believe when it comes to } \\
\text { inheritance, no matter what I could have done, I would develop }\end{array}$ & $\begin{array}{l}\text { No effect of preventative } \\
\text { behaviors }\end{array}$ & $\begin{array}{l}\text { Treatment } \\
\text { efficiency }\end{array}$ & $\begin{array}{l}\text { Heart diseases are hereditary } \\
\text { and have no way to prevent. }\end{array}$ \\
\hline
\end{tabular}




\section{Results}

In this study 319 codes were extracted from the analyzing phase which formed 6 categories including prognosis, prevention, contexts, treatment efficiency, mentality and lifestyle as well as 9 sub-categories including understanding the danger, attitude toward disease, attitude toward treatment, society's culture, feeling hopeless, treatment regimen ignorance, self-curing, trying to survive and physical outcomes.

The early items' pool was formed with 58 items after the literature review. Initial codes were examined by the research team, and similar items were deleted. Eventually, the pool included 58 items. These 58 items were evaluated for formal (quantitative and qualitative) validity. Four items were reviewed in terms of qualitative and quantitative face validity, and 5 items that received the score of 1.5 or less in the face validity were eliminated. A 53 -item questionnaire remained at the end. Then 2 items were reviewed in the content validity check and all the possible changes were applied. The quantitative survey of content validity was based on the CVR and CVI methods. Fourteen items were eliminated using CVR method. Three other items were also ignored after receiving a score of $0.71,0.71$ and 0.73 , respectively, in the CVI method. The mean content validity score (S-CVI) for all the remaining items was equal to 0.92 in the next step.

A 36-item questionnaire based on 5-point Likert scale (4 for strongly agree and 0 for strongly disagree) was prepared from the exploratory content analysis phase. The total internal consistency was found to be 0.89 in the early reliability check. 3 items were removed in the internal consistency check of each item. EFA was used in the evaluation of the factor structure of the scale. Analyzing the main components was done by varimax rotation on the 33 -item questionnaire. The KMO value of 0.7 or higher was considered as the condition of sample size sufficiency in the content analysis. The Bartlett test with the final value of 2560.2 was also considered as significant $(p<0.001)$, meaning that there was enough consistency among the items for factor analysis.

The KMO was obtained at 0.89. Meanwhile, Bartlett's test of sphericity at 7290.841 was significant at 0.0001 level and 525 degree of freedom $(\mathrm{p}=0.001)$.

Eigenvalues of above one and the scree plot were used to determine the number factors in the instrument. Answers with factor loadings equal to or above 0.4 were considered acceptable. In this stage, 3 items were removed. In this regard, six factors and 30 items with eigenvalues above one and loading level equal to or above 0.4 were extracted (Table 2). The scree plot also confirmed the existence of six factors (Fig. 1). After that, the analysis was performed with these six factors as the foundation. The six-factor solution explained $51.7 \%$ of the total variance.

To evaluate the internal consistency, the Cronbach's alpha was calculated for each item and totally, which was 0.95. The test-retest method was used for probing the stability. The results showed that the scores of first and second tests were statistically significant $(p<0.001$ and

Table 2. Results of EFA Using Rotated Component Matrix

\begin{tabular}{|c|c|c|c|c|c|c|c|}
\hline $\mathrm{NO}$ & Items & & & Con & & & \\
\hline$\overline{1}$ & Heart-related problems at any age can shorten your life for sure. & 1 & 2 & 3 & 4 & 5 & 6 \\
\hline 2 & It is important to avoid any factor resulting in angina or chest pain. & 0.694 & & & & & \\
\hline 3 & It is impossible to renew a damaged heart. & 0.502 & & & & & \\
\hline 4 & It is important to be ready for a heart attack. & 0.525 & & & & & \\
\hline 5 & Heart attack is accompanied by chest pain. & 0.502 & & & & & \\
\hline 6 & Changes in lifestyle can decrease the rate of further heart attacks. & 0.504 & & & & & \\
\hline 7 & Blood cholesterol control is not needed before aging. & & 0.569 & & & & \\
\hline 8 & Diabetes treatment decreases the heart-related problems. & & 0.592 & & & & \\
\hline 9 & Stress is of the main reasons for heart diseases. & & 0.750 & & & & \\
\hline 10 & Heart diseases are hereditary and have no way to prevent. & & & 0.548 & & & \\
\hline 11 & This disease is prevalent among men mostly. & & & 0.602 & & & \\
\hline 12 & Continues use of drugs is worrying. & & & 0.511 & & & \\
\hline 13 & There is no need for drugs in case the blood pressure is normal. & & & & 0.622 & & \\
\hline 14 & Resting is the best treatment for heart diseases. & & & & 0.553 & & \\
\hline 15 & Death by heart disease is Divine destiny. & & & & 0.514 & & \\
\hline 16 & Heart attack weakens the heart wall and tears the heart rapidly. & & & & & 0.556 & \\
\hline 17 & Heart is like a battery; more work, more exhaustion. & & & & & 0.594 & \\
\hline 18 & Heart diseases are mostly coming from the patients' lifestyle. & & & & & 0.654 & \\
\hline 19 & Aging makes the heart weaker and farther from doing the right job. & & & & & 0.563 & \\
\hline 20 & $\begin{array}{l}\text { Heart disease has some limitations alongside but not much important } \\
\text { problems. }\end{array}$ & & & & & 0.562 & \\
\hline 21 & Experiencing post-heart disease life is impossible. & & & & & 0.600 & \\
\hline 22 & Heart disease is part of body deterioration. & & & & & 0.567 & \\
\hline 23 & $\begin{array}{l}\text { Continues use of drugs is the only way for staying alive after getting heart } \\
\text { problems. }\end{array}$ & & & & & 0.513 & \\
\hline 24 & Health literacy is important in heart-related problems prevention. & & & & & 0.522 & \\
\hline 25 & The sudden incidence of heart problems increases the damages. & & & & & 0.517 & \\
\hline 26 & Getting heart disease is like catching a cold. It's easy to deal with it. & & & & & 0.592 & \\
\hline 27 & It is necessary to avoid any stress or mental pressure for a cardiac patient. & & & & & & 0.509 \\
\hline 28 & Unhealthy and abnormal food intake is harmful to a cardiac patient. & & & & & & 0.537 \\
\hline 29 & $\begin{array}{l}\text { Any kind of physical activity, even walking, is dangerous for a cardiac } \\
\text { patient. }\end{array}$ & & & & & & 0.581 \\
\hline 30 & Cardiac patients should avoid being in society/social places. & & & & & & 0.608 \\
\hline
\end{tabular}


Scree Plot

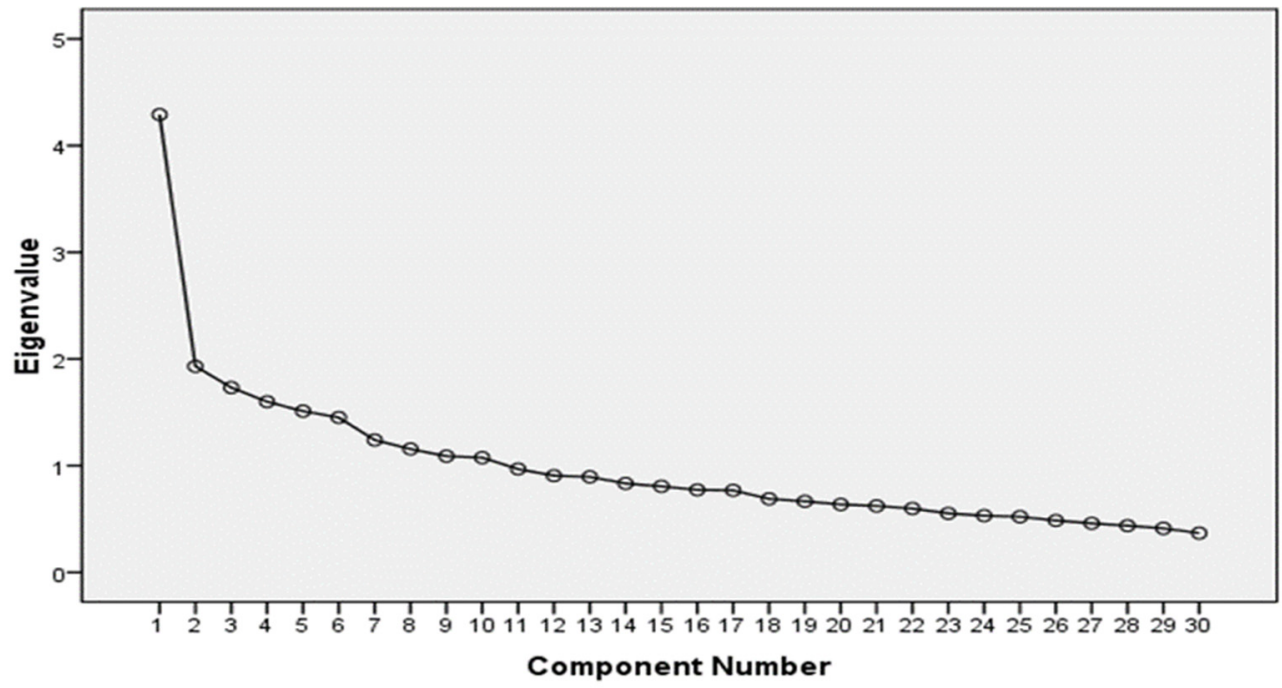

Fig. 1. Score plot in the questionnaire on cardiac patients beliefs about illness and treatment

Table 3. Intraclass Correlation Coefficient and Cronbach's Alpha Values of six Factors

\begin{tabular}{lcccc}
\hline factor & Subscale & $\mathrm{N}$ & Cronbach's Alpha & Intraclass Correlation Coefficient \\
\hline 1 & prognosis & 5 items (1-5) & 0.76 & 0.77 \\
2 & prevention & 3 items $(6-8)$ & 0.83 & 0.85 \\
3 & contexts & 3 items $(9-11)$ & 0.78 & 0.79 \\
4 & treatment efficiency & 3 items $(12-14)$ & 0.81 & 0.83 \\
5 & mentality & 12 items $(15-26)$ & 0.89 & 0.89 \\
6 & lifestyle & 4 items (27-30) & 0.82 & 0.84 \\
Total & The whole questionnaire & 30 items & 0.83 & 0.85 \\
\hline
\end{tabular}

$\mathrm{ICC}=0.83$ ), approving the repeatability of the subscales and the questionnaire besides showing high stability (Table 3).

The questionnaire included six subscales including prognosis, prevention, contexts, treatment efficiency, mentality, and lifestyle. The scoring scale in this questionnaire was based on the five-point Likert scale denoting strongly agree score with 4 to strongly disagree score with 1. The questions $1,3,10,11,12,13,15,16,21,26,29$ and 30 are scored negatively. where the line cutting score is considered to be 48 meaning that reciving the score of 48 or less shows false beliefs and the higher scores indicate true beliefs about the disease and the treatment process.

\section{Discussion}

Each item showed a fair relationship with one of the subscales, and the structural validity degree of mean correlation seemed to be reasonable, as indicated by the load factor of each item. The statistically significant relationship between the subscales and total score of the questionnaire was observed (25).

The reliability of the scale was checked both by the internal consistency and retest methods, thus, strengthening the reliability test results. The results showed that the questionnaire has good internal consistency. However, further analysis on bigger scales may show stronger relationships. This questionnaire can assess the cardiac patients' beliefs about illness and treatment in all the six domains of prognosis, prevention, contexts, treatment efficiency, mentality, and lifestyle. Further surveys for using the questionnaire in bigger cultures and populations is needed.

Recognizing and treating the disease both have very important roles in promoting health-related behaviors (26). Patients' beliefs about cardiac diseases are crucial to appreciating the disease, following the treatment process and satisfaction from the process (27).

Questionnaires to assess specific beliefs and understanding in heart disease have also been developed and may be used in clinical settings to investigate patients' illness beliefs - for example, the York angina questionnaire (28) and the cardiac misconceptions scale (29).

Recognizing the patients' beliefs is an important aspect of caring permanence of cardiac disease sufferers. Reforming the beliefs and behaviors of mentioned patients by improving the skills, role behaving, and behavioral interventions for accommodating the patient and his family members with the cardiac disease (30). Recognizing the patients' beliefs gives the chance of exploring the situation from the patients' viewpoint. This psychological approach can be achieved by patients' own guidance throw their beliefs.

\section{Conclusion}

This questionnaire, which we recommend as a mini scale, can be used both in statistical and practical studies. It can be used in health systems as a scale for probing and examining the cardiac patients' beliefs about illness and treatment, and it can help for assessing each patient's edu- 
cational needs. On the other hand, this scale can assess the true or false beliefs; therefore, it can be used for providing the appropriate intervention at the first, second and the third level of prevention based on client needs.

Within the clinical context, a consideration of both types of belief in patients will lead to the more patientcentered approach and are likely to lead to more effective management and patient care.

Screening the beliefs by the use of this tool leads the healthcare providers to select an appropriate intervention to change the patients' behaviors. In other words, recognizing the beliefs can result in designing more effective interventions by the policymakers and experiencing healthier lifestyle among the patients.

\section{Ethical considerations}

The ethical considerations mentioned by the researchers include receiving Tehran University of Medical Sciences ethics committee approval, receiving participation consent after stating the research aims from the participants, giving the right of withdrawal from the study at any stage to the participants, keeping participants' secrecy and providing the results to the participants in case of requesting for.

\section{Acknowledgments}

This project has been registered at Nursing and Midwifery Care Research Center of Tehran University of Medical Sciences with the registration number of 26139. We do appreciate all the cardiac patients and facultymembers helped us for doing this research.

\section{Conflict of Interests}

The authors declare that they have no competing interests.

\section{References}

1. Dracup K, McKinley S, Riegel B, Mose DK, Meischke H, Doering LV, et al. A Randomized Clinical Trial to Reduce Patient Prehospital Delay to Treatment in Acute Coronary Syndrome. Circ Cardiovasc Qual Outcomes. 2009;2(6):524-32.

2. Taghaddosi M, Dianati M, Fath-Gharib-Bidgoli J, Bahonaran J. Delay and its Related Factors in Seeking Treatment in Patients with Acute Myocardial Infarction. ARYA Atheroscler. 2010 6(1):35-41.

3. Iranian-Statistics-Center. Annual Report of the Iranian Statistics Center. Tehran: National Statistics Center; 2009.

4. Abbaszadeh A, Borhani F, Asadi N. Effects of health belief modelbased video training about risk factors on knowledge and attitude of myocardial infarction patients after discharge. J Res Med Sci. 2011;16(2):195-9.

5. Stafford L, Jackson H, Berk M. Illness Beliefs About Heart Disease and Adherence to Secondary Prevention Regimens. Psychosom Med. 2008;70(8):942-8.

6. Lin YP, Wang TJ, Tung HH, Furze G. Coronary heart disease beliefs and misconceptions among cardiac patients and people with chronic illness. Open J Nurs. 2012;2:1-7.

7. Ogden J. Health psychology: A textbook. 4 ed: Open University Press, Berkshire; 2007.

8. Juergens MC, Seekatz B, Moosdorf RG, Petrie KJ, Rief W. Illness beliefs before cardiac surgery predict disability, quality of life, and depression 3 months later. J Psychosom Res. 2009;11:1-8.

9. Mirmohammadi J, Sadr-Bafghi M, Mehrparvar AH, Gharavi M, Davari MH, Bahaloo M, et al. Evaluation of the return to work and its duration after myocardial infarction. ARYA Atheroscler. 2014;10(3):137-40.

10. Giallauriaa F, Vigoritoa C, Piepolic MF, Coatsd AJS. Effects of cardiac contractility modulation by non-excitatory electrical stimulation on exercise capacity and quality of life: An individual patient's data meta-analysis of randomized controlled trials. Int $\mathrm{J}$ Cardiol. 2014;175(2): 352-7.

11. Antiel RM, Bos JM, Joyce DD, Owen HJ, Roskos PL, Moir C, et al. Quality of life after videoscopic left cardiac sympathetic denervation in patients with potentially life-threatening cardiac channelopathies/cardiomyopathies. Heart Rhythm. 2016;13(1):62-9.

12. Clark V, Creswell J. Designing and conducting mixed methods research. Thousand Oaks (California): Sage Publications; 2011.

13. Vaismoradi M, Turunen H, Bondas T. Content analysis and thematic analysis: Implications for conducting a qualitative descriptive study. Nurs Health Sci. 2013;15:398-405.

14. Guba EG, Lincoln YS. Competing paradigms in qualitative research. Handbook of qualitative research. 1994;2(163-194).

15. Dutt N, Chaudhry K, Chauhan NK, Kuwal A, Saini LK, Purohit S, et al. Health Related Quality of Life in Adult Obstructive Sleep Apnea. J Sleep Disord Ther. 2016;5(2):1-7.

16. Lawshe C. A quantitative approach to content validity1. J Pers Psychol. 1975;28(4):563-75.

17. Yaghmale F. Content validity and its estimation. Med Educ. 2009;3(1).

18. Polit D, Beck C. Resource manual for nursing research: Generating and assessing evidence for nursing practice: Wolters Kluwer Health/Lippincott Williams \& Wilkins; 2012.

19. Doward L, Meads D, Thorsen H. Requirements for quality of life instruments in clinical research. Value Health. 2004;7(1):13-6.

20. Gray J, Grove S, Sutherland S. Burns and Grove's The Practice of Nursing Research Appraisal, Synthesis, and Generation of Evidence, 8th Edition. Saunders. 2016.

21. Shali M, Ghaffari F, Joolaee S, Ebadi A. Development and Psychometric Evaluation of the Patient Safety Violation Scale in Medical Oncology Units in Iran. Asian Pac J Cancer Prev. 2016;17(9):4341-7.

22. Krishna H, Kumar K. Reliability estimation in generalized inverted exponential distribution with progressively type II censored sample. J Stat Comput Simul. 2013;83(6):1007-19.

23. Šerbetar I. Establishing Some Measures of Absolute and Relative Reliability of a Motor Tests. Croat J Educ. 2015;17(1):37-48.

24. Yong AG, Pearce S. A Beginner's Guide to Factor Analysis: Focusing on Exploratory Factor Analysis. Tutor Quant Methods Psychol. 2013;9(2):79-94.

25. Beavers AS, Lounsbury JW, Richards JK, Huck SW, Skolits GJ, Esquivel SL. Practical Considerations for Using Exploratory Factor Analysis in Educational Research. Pract assess res eval. 2013;18(6):113.

26. Gaskina CJ, Happell B. On exploratory factor analysis: A review of recent evidence, an assessment of current practice, and recommendations for future use. Int J Nurs Stud. 2014;51(3):511-21.

27. Hirani SP, Patterson DL, Newman SP. What do coronary artery disease patients think about their treatments? An assessment of patients' treatment representations. J Health Psychol. 2008;13(3):31122.

28. Furze G, Bull P, Lewin RJ, Thompson DR. Development of the York angina beliefs questionnaire. J Health Psychol. 2003;8(3):30715.

29. Mæland JG, Havik OE. Self-assessment of health before and after a myocardial infarction. Soc Sci Med. 1988;27(6):597-605.

30. Lin YP, Spilsbury K, Furze G, Lewin RJ. Exploring misconceptions or potentially maladaptive beliefs about coronary heart disease and their relationship with coping behaviours among Taiwanese cardiac patients. Divers Equal Health Care. 2009;6:97-108. 